should be given if the infection is primary, if any of the cultures from the infant are positive, or if the infant's condition shows cause for concern.

The babies who are given acyclovir should then be carefully followed up so that we may learn about the efficacy of such treatment.

JOHN KELLY

Consultant Obstetrician and Gynaecologist,

Birmingham Maternity Hospital,

Birmingham B15 2TG
1 Whitley RJ. Neonatal herpes simplex virus infections. I Reprod Med 1986;31:26-32.

2 Woodman CBJ, Weaver JB. Virological screening for herpes simplex virus $(\mathrm{H} ; \mathrm{V})$ in late pregnancy. Lancet 1986; ;: 744 .

3 Woolley PD, Bowman CA, Hicks DA, Kinghorn GR. Virological screening for herpes simplex virus during pregnancy. $\mathrm{Br}$ Med $\mathcal{F}$ 1988;296:1642-3.

4 Carney O, Mindel A. Screening pregnant women for genital herpes. Br Med: 1988;296:1643.

5 Arvin AM, Hensleigh PA, Prober CG, et al. Failure of antepartum maternalcultures to predict the infant's risk of exposure to herpes simplex virus at delivery. $N$ Engl f Med 1986;315:796-800.

6 Prober CG, Hensleigh PA, Boucher FD, Yasukawa LL, Au DS, Arvin AM. Use of routine viral cultures at delivery to identify neonates exposed to herpes simplex virus. $N$ Engl $\mathcal{F}$ Med 1988:318:887-91.

7 Brown ZA. Current considerations in the obstetric and gynecologic management of herpes simplex virus infections. F Reprod Med 1986;31:450.

8 Kaufman RH. Current considerations in the obstetric and gynecologic management of herpes simplex virus infections. F Reprod Med 1986;31:445.

9 Stone KM. Current considerations in the obstetric and gynecologic nanagement of herpes simplex virus infections. F Reprod Med 1986;31:452.

\title{
Childhood tuberculosis in Britain
}

\section{Going but not gone}

Notification of tuberculosis in white children in England and Wales declined by $7 \%$ each year between 1978 and 1983 . The decline was steeper among Asian children (mostly born in Britain) of Indian (14\%) and of Pakistani or Bangladeshi origin (10\%). Nevertheless, the $5 \%$ of children in Britain who are of Asian origin account for almost half of the notifications. In 1983 the rates of notification were 2.4 per 100000 for white children, 40 per 100000 for Asian children, and 17 per 100000 for children of West Indian origin.

Of prime importance in the decline in childhood tuberculosis is the decline in the incidence of adult tuberculosis, the source of infection in most children. ${ }^{1}$ Another factor is BCG immunisation at 13, which has been standard practice in Britain for 35 years. It gives over $75 \%$ protective efficacy for at least 10 years. ${ }^{23}$ Effective treatment of adult cases has also been important, and the fact that resistance to drugs is so unusual in British children with tuberculosis is testimony to the care with which drug treatment is monitored. ${ }^{1}$ Prophylactic chemotherapy in children who have been exposed to tuberculosis and show a positive reaction to the tuberculin test is an effective means of preventing the active tuberculosis that often follows conversion. ${ }^{4}$ Finally, tracing of contacts by health visitors from chest clinics has contributed to the decline of tuberculosis. Almost half of the cases in children notified in 1983 were diagnosed through tracing of contacts. ${ }^{1}$

The decline of tuberculosis means that BCG vaccination at 13 will soon become less cost effective in preventing tuberculosis in young adults and will be withdrawn. Nevertheless, children are still at risk. Outbreaks of tuberculosis may occur after contact with a highly infectious adult in Britain, ${ }^{5}$ and greater travel overseas increases the scope for infection or even reinfection. ${ }^{6}$

If $B C G$ vaccination at 13 is withdrawn it may be completely replaced by vaccination in infancy, but a recent paper and one published today ( $p$ 1173) on the technique and efficacy of BCG vaccination in infants remind us that many questions remain unanswered. ${ }^{7}$ Three techniques are available for giving the vaccination: intradermal injection, jet injection, and multiple puncture by a modified Heaf gun. They probably give similar degrees of conversion as measured by Mantoux or Heaf testing. ${ }^{78}$ The method of intradermal injection has the greatest potential for local complications and demands high skill in the operator. (It should not be "left to the senior house officer.") The jet injector is a tempting but temperamental device that has proved fallible in the Third World. Perhaps the technique of using the modified Heaf gun should be given a more thorough assessment.
To determine the true efficacy of $\mathrm{BC}\}$ vaccination would require a large controlled trial. The case-control technique provides a short cut. In Birmingham frcm 1965 to 1979 BCG vaccination was offered by intradermal injection at 3 months to some 30000 children of Asian origin. ${ }^{7}$ Among those who accepted vaccination, $92 \%$ subsequently gave a positive result to the Mantoux test. Tuberculosis was later diagnosed in 108 Birmingham children. Each infected child was matched for age, sex, and ethnic origin with four controls. The rate of BCG vaccination was lower in cases $(57 \%)$ than in controls $(78 \%)$, and the estimated protective efficacy was $64 \%$ (95\% confidence interval $43 \%$ to $77 \%$ ). The precise degree of protection is questionable as this study could be seriously biased. The reasons for failure to vaccinate $43 \%$ of cases and $22 \%$ of controls were not adequately given, but non-compliance with immunisation programmes is greater among poorer families. Might tuberculosis have been commoner among the parents of unvaccinated children? In support of the Birmingham data a high degree of protection was also found in a follow up study of infants in Manchester. ${ }^{9}$ Rates of protection were similar for Asian and non-Asian children, and BCG vaccination of infants seems effective in Britain. The duration of protection is unknown.

The risk of disseminated tuberculosis is highest in infancyso the earlier vaccination is given the better. Certainly a campaign to vaccinate the captive population in the postnatal ward is likely to be more complete than one conducted from child health clinics. Cell mediated immunity may, however, be less efficient immediately after birth, ${ }^{10}$ and a case has thus been made for deferring BCG vaccinations until two to three months after birth. This is not born out, however, by the high rates of conversion on tuberculin testing in infants given $B C G$ within 10 days of birth. ${ }^{81}$ Again, without a clinical trial the ideal age for BCG vaccination is not known.

In Asian children who are at high risk of tuberculosis BCG vaccination in infancy will provide important protectio..$^{7912}$ The children of families in whom tuberculosis has been previously identified, those travelling to Third World countries and children from areas of social deprivation ${ }^{12}$ should also be offered BCG. Infants at low risk should not be totally excluded; despite the risk of local complications anc the incomplete protection afforded some parents will want their children vaccinated.

Most of our information on BCG vaccination in infancy comes from uncontrolled or small (pilot) studies. A properly controlled investigation should compare technique: of vaccination, age at vaccination, and outcome. In evalusting 
the outcome, we must consider not only the benefits. Because infants may remain positive for tuberculin for several years ${ }^{11}$ the tuberculin test is devalued as a diagnostic aid, which may lead to an incieased need for chemoprophylaxis. Doctors still have a large responsibility for diagnosing the dwindling condition of shildhood tuberculosis and for ensuring that tracing of contacts is carried out assiduously.

Reader in Paediatric Fespiratory Medicine,

MICHAEL SILVERMAN

Royal Postgraduate Medical School,

London W12 0HS

Medical Research Council Tuberculosis and Chest Diseases Unit. Tuberculosis in children: national survey of notifictions in England and Wales. Arch Dis Child 1988;63:266-76.
Research Committee of the British Thoracic Association. Effectiveness of BCG vaccination in Great Britain in 1978. Brf Dis Chest 1980;74:215-27.

Sutherland I, Springett VH. Effectiveness of BCG vaccination in England and Wales in 1983. Tubercle 1987;68:81-92.

4 Ormerod LP. Reduced incidence of tuberculosis by prophylactic chemotherapy in subjects showing strong reactions to tuberculin testing. Arch Dis Child 1987;62:1005-8.

George RH, Gully PR, Gill ON, Innes JA, Bakhshi SS, Connolly M. Outbreak of tuberculosis in a children's hospital. $\mathcal{F}$ Hosp Infect 1986;8:129-42.

$6 \mathrm{McCarthy}$ OR. Asian immigrant tuberculosis-the effect of visiting Asia. $\mathrm{Br} \mathcal{F}$ Dis Chest 1984;78:248-53.

7 Packe GE, Innes JA. Protective effect of BCG vaccination in infant Asians: a case-control study. Arch Dis Child 1988;63:277-81

8 Hadfield JW, Allan J, Windebank WJ. Sensitivity of neonates to tuberculin after BCG vaccination Br Med f 1986;292:990-1.

9 Curtis HM, Leck I, Bamford FN. Incidence of childhood tuberculosis after neonatal BCG vaccination. Lancet 1984; i: 145-8.

10 Chandra PK. Serum thymic hormone activity and cell mediated immunity in healthy neonates, preterm infants and small for gestational age infants. Pediatrics 1981;67:407-11.

11 Grindulis I, Baynham MID, Scott PH, Thompson RA, Wharton BA. Tuberculin response two years after BCG vaccination. Arch Dis Child 1984;59:514-612.

12 Cundall DB, Pearson SB. Inner city tuberculosis and immunisation policy. Arch Dis Child 1988;63:964-6.

\section{Social security benefits for the mentally ill}

\section{Uptake is low and information is sparse}

One result of mentaly ill people being cared for more in the community and less in hospital is that more of them are having to cope with a complex, bureaucratic, and often seemingly hostile social securitysystem. Yet the changes in the system in April 1988 make it even more important that these people cope with the system-for example, claiming an attendance allowance is crucial as it is a "passport" to higher income support or housing benefits. We have little or no information on how the mentally ill are coping with the new system, and, indeed, until last year almost nothing had been published on the mentally ill and social security. Islington People's Rights did something to correct this ignorance by publishing a study of the uptake of social security benefits by the mentally ill in the borough. ${ }^{1}$

Contrary to assumptions that patients in hospital were correctly advised about benefits, the study showed that, although some help was available, important benefits were unclaimed. For example, there was serious underutilisation of the attendance allowance available to patients spending part of their time at home and needing constant or frequent supervision there because claims had not been made on their behalf. Patients about to be discharged from hospital had not been informed about the benefits they should claim. Successful integration into the community depends to some extent on freedom from financial concerns, and the absence of information is worrying.

As part of the study a detailed questionnaire about welfare benefits was given to 28 patients, 24 of whom were unemployed, attending day centres or outpatient departments. More than half of those attending outpatient departments were not receiving benefits to which they were entitled but had not laid claim. This study suggested that the mentally ill were in this respect more disadvantaged than the physically ill. Over a third of the subjects interviewed confessed to having debts and experiencing severe financial strain, a further source of stress for a vulnerable group of patients. Several interviewees made critical comments about the benefits system and the attitudes they encountered at offices of the Department of Health and Social Security. These problems may have been caused by understaffing in local offices or may reflect social attitudes to mental illness.

In the long term we need a social security system more sensitive to the needs of special groups such as the mentally ill. In the short term the problems might be lessened by the routine provision of information about benefits for patients about to be discharged from hospital, residents of local authority hostels and group homes, and patients attending community day centres for the mentally ill. This provision probably exists in many units, but it should be generally available. Additionally, welfare rights officers should be alerted to the particular needs of the mentally ill, and community psychiatric nurses and social workers should be trained to tell their clients about their rights to benefits.

These comments are based on the findings of a small study in a single health district, and after extensive inquiry I failed to uncover other sources of information about the utilisation of the social security system by the mentally ill. Islington People's Rights is to be congratulated for highlighting an important deficit in care, but more studies are needed. Readiness to fund such research is a measure of society's concern about the lot of the mentally ill.

Senior Lecturer in General Practice,

B E MARKS

University of Manchester,

Rusholme Health Centre,

Manchester M14 5NP

1 Linney J, Boswell C. Social security and mental illness. London: Islington People's Rights, 1987.

\section{Correction}

Regular Review: Echocardiography

We regret that in this regular review by Dr J B Chambers and others (29 October, p 1071) the pictures in figure 5 were transposed. 